$\underset{\text { clinical }}{\text { nephron }}$

Practice
Nephron 2019;143:33-37

DOI: 10.1159/000495665
Received: September 27, 2018

Accepted after revision: November 21, 2018

Published online: January 16, 2019

\title{
Beta Cell Functional Adaptation and Dysfunction in Insulin Resistance and the Role of Chronic Kidney Disease
}

\author{
Andraž Stožer $^{a}$ Radovan Hojs $^{b, c}$ Jurij Dolenšek ${ }^{a, d}$ \\ ${ }^{a}$ Institute of Physiology, Faculty of Medicine, University of Maribor, Maribor, Slovenia; ${ }^{\text {b } F a c u l t y ~ o f ~ M e d i c i n e, ~}$ \\ University of Maribor, Maribor, Slovenia; ' ${ }^{\top}$ Department of Nephrology, Clinic for Internal Medicine, University \\ Medical Centre Maribor, Maribor, Slovenia; ${ }^{\mathrm{d}}$ Faculty of Natural Sciences and Mathematics, University of Maribor, \\ Maribor, Slovenia
}

\section{Keywords}

Beta cell · Adaptation · Dysfunction · Urea

\begin{abstract}
Background: Beta cells are central in the pathophysiology of diabetes, since their functional adaptation maintains euglycemia in insulin-resistant individuals and beta cell dysfunction is required for the clinical picture of frank diabetes. The pathophysiological mechanisms driving compensation and decompensation are incompletely understood and little is known about the influence of chronic kidney disease (CKD) on beta cell function. Summary: In compensated insulin resistance, beta cells enhance their function at all stages in the stimulus-secretion coupling cascade, from the most proximal membrane depolarization to the intermediate increase in intracellular calcium concentration and the most distal granule fusion. Intercellular coupling is not disrupted at this early stage during disease progression. Later during progression, when hyperglycemia becomes more apparent owing to in-
\end{abstract}

sufficient beta cell compensation, intracellular stimulus-secretion coupling becomes enhanced to an even larger degree, but intercellular coupling becomes disrupted, indicating that ineffective cell-to-cell signal transmission may be the earliest event in progression to frank diabetes. CKD can negatively affect beta cell function through increased levels of urea that reduce beta cell glucose utilization and impair insulin secretion, and possibly also through factors other than urea. It remains to be investigated whether urea and other factors of CKD can also affect intercellular coupling. Key messages: Beta cells enhance intracellular stimulus-secretion coupling in early insulin resistance. With worsening insulin resistance, intracellular coupling enhances even more, but intercellular coupling becomes disrupted. CKD negatively impacts beta cell function, but its influence on intercellular coupling awaits further studies.

(c) 2019 S. Karger AG, Basel

Contribution from the CME Course of the DIABESITY Working Group of the ERA-EDTA, Lisbon, November 24-25, 2017.

\section{KARGER}

(C) 2019 S. Karger AG, Basel

E-Mail karger@karger.com

www.karger.com/nef
Andraž Stožer, $\mathrm{MD}, \mathrm{PhD}$ and Jurij Dolenšek, $\mathrm{PhD}$

Institute of Physiology

Faculty of Medicine, University of Maribor

Taborska Ulica 8, SI-2000 Maribor (Slovenia)

E-Mail andraz.stozer@um.si and jurij.dolensek@um.si 


\section{Introduction}

Our knowledge of type 2 diabetes etiopathogenesis is limited to a detailed description of its natural history from insulin resistance to decreased insulin secretion and overt hyperglycemia, and to a long list of potential mechanisms responsible for both insulin resistance and decreased insulin secretion. We know less about the mechanisms driving the transient compensatory phase of hyperinsulinemia maintaining a state of euglycemia before progression to beta cell failure $[1,2]$. An important component of this compensatory phase could be increased beta cell mass due to beta cell hyperplasia, and partly due to beta cell hypertrophy, although the evidence is not equivocal [3]. However, the structurally increased beta cell mass cannot entirely account for the increased pancreatic insulin release, and each individual beta cell probably also enhances its secretory capacity in the face of insulin resistance. The eventual failure of this adaptive response, together with beta cell dedifferentiation and apoptosis, is probably critical for progression from compensation to decompensation and type 2 diabetes [2-4]. Conceivably, hyperinsulinemia is not always a consequence of insulin resistance but can arise due to a number of other genetic and environmental factors. Most importantly, there is experimental evidence showing that hyperinsulinemia can sometimes precede insulin resistance and via its effects in target tissues actually contribute to it $[5,6]$. In any event, understanding the crucial steps in beta cell functional adaptation and failure holds promise to identify new targets for prevention and treatment [2-4].

\section{Normal Beta Cell Stimulus-Secretion Coupling}

Beta cells are the most abundant endocrine cells in pancreatic islets of Langerhans [7]. They couple stimulation by various secretagogues with insulin secretion through the process of stimulus-secretion coupling (Fig. 1). The best-described signaling cascade involves glucose as a fuel secretagogue, leading to glucose-stimulated insulin secretion (GSIS). Glucose enters the cell through GLUT2, is metabolized through glycolysis and oxidative phosphorylation to yield ATP, in turn closing $\mathrm{K}_{\mathrm{ATP}}$ channels. The resulting membrane depolarization activates voltage-dependent calcium channels, leading to action potentials and entry of calcium. This triggers exocytosis of insulin-containing granules, and activates calcium-dependent potassium channels, the latter lead- ing to periodic electrical activity in the form of bursts of action potentials. Periodic membrane depolarizations, cytosolic calcium concentration $\left(\left[\mathrm{Ca}^{2+}\right]_{c}\right)$ changes and secretory pulses are well synchronized between cells, owing to intercellular coupling by gap junctions consisting of connexin 36 . In addition to this triggering pathway, there are other modes of action of glucose and pathways initiated by hormones and neurotransmitters [1].

\section{Beta Cell Functional Adaptation and Failure in Response to Insulin Resistance}

A few recent studies can help us understand which stages in stimulus-secretion coupling most robustly change in response to insulin resistance, defined here mechanistically as a decreased response of target tissues to insulin (Fig. 1). In high-fat diet (HFD)-induced hyperinsulinemic C57BL/6J mice, increased beta cell number and size were accompanied by larger amplitudes of action potentials, augmented $\left[\mathrm{Ca}^{2+}\right]_{c}$, and an increased exocytotic efficiency, resulting in enhanced GSIS [2]. In particular, both the amplitude of the first transient increase in $\left[\mathrm{Ca}^{2+}\right]_{c}$ and the area under the curve during glucose stimulation were increased, together with a better recruitment of beta cells. Another very important parameter of GSIS, intercellular synchronization, did not change in HFD, although $\left[\mathrm{Ca}^{2+}\right]_{c}$ signals from only a few individual beta cells in isolated islets were compared to assess the degree of coupling. Augmented $\left[\mathrm{Ca}^{2+}\right]_{\mathrm{c}}$ signaling was not observed in response to a non-metabolic stimulus $(\mathrm{KCl})$, indicating that the observed increase in GSIS is due to glucose metabolism. Importantly, the open probability of $\mathrm{K}_{\mathrm{ATP}}$ channels, the resting membrane potential, and membrane potential at the foot of the action potentials were not different from the ones in normal mice, suggesting that the responsible metabolic factor is not ATP and that the modulated targets are distally from the $\mathrm{K}_{\mathrm{ATP}}$ channel in the stimulus-secretion coupling cascade. This was further supported by the finding that mitochondrial hyperpolarization in response to stimulation with glucose was similar in HFDfed and control mice. The authors suggested that the responsible metabolite mediating the functional adaptations might be the reduced nicotinamide adenine dinucleotide or glutamate, acting either on a non- $\mathrm{K}_{\mathrm{ATP}}$ potassium channel or calcium channels to augment $\left[\mathrm{Ca}^{2+}\right]_{\mathrm{c}}$, or increasing the sensitivity of the exocytotic machinery to $\left[\mathrm{Ca}^{2+}\right]_{\mathrm{c}}[2]$. 

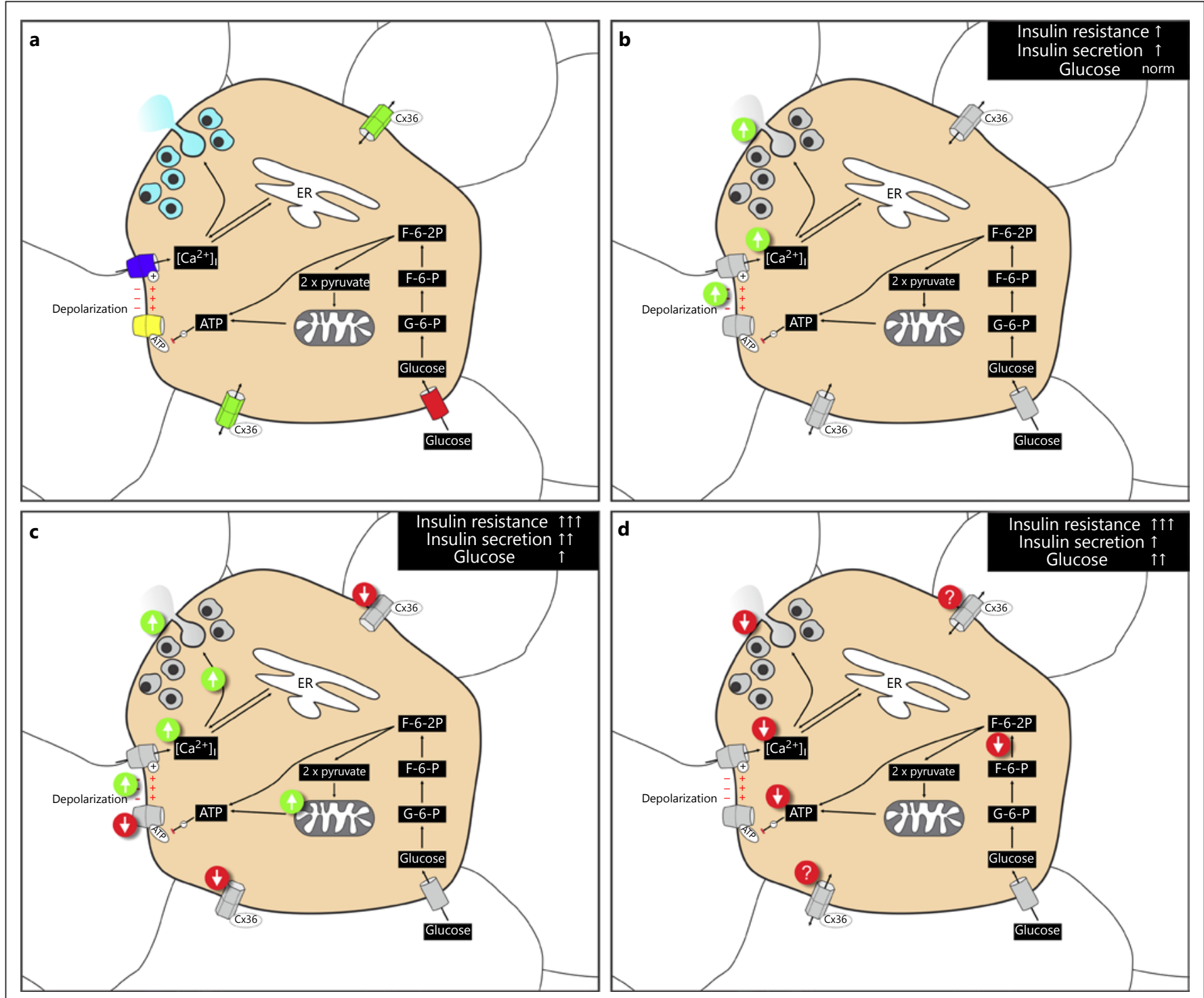

Fig. 1. a Normal beta cell stimulus-secretion coupling. b Positive adaptations (upwards arrows) in beta cell stimulus-secretion coupling that compensate for an increased insulin resistance, as occurs in HFD-fed mice. c Positive (upwards arrows) and negative (downwards arrows) adaptations that underlie the incomplete compen-

Female $o b / o b$ mice have a greater degree of glucose intolerance and are thus a better model for the intermediate stage between compensated and decompensated insulin resistance. In addition to an increased islet size, many functional adaptations but also an early sign of dysfunction were found in these mice. First, in contrast to the milder phenotype in HFD-fed mice, ob/ob mice had an enhanced glucose-induced metabolism, evidenced by increased mitochondrial hyperpolarization and NADPH

sation for the further increased insulin resistance, as it occurs in ob/ob mice, for instance. d Chronic kidney disease negatively affects beta cell function at different stages in stimulus-secretion coupling (downwards arrows). See text for more details.

fluorescence. This enhanced metabolism was probably not due to the entry of glucose and glycolysis, since the expression of GLUT2 was lower and that of glucokinase not different from controls. Second, the electrical activity displayed a higher frequency of action potentials, longer bursts, longer interburst intervals, and more depolarized membrane potentials at the beginning of the bursts as well as action potentials and peaks of action potentials, implying an altered activity of calcium-dependent potas-

Beta Cell Functional Adaptation and 
sium channels. Similar differences as in HFD-fed mice were found at the level of $\left[\mathrm{Ca}^{2+}\right]_{c}$. Especially, the amplitude of the transient increase and area under the curve were increased in low glucose concentrations, indicating a left shift in sensitivity, which was further supported by a reduced time lag to the onset of the response. $\left[\mathrm{Ca}^{2+}\right]_{c}$ changes in intermediate glucose concentrations reflected well the changes in electrical activity, with slower $\left[\mathrm{Ca}^{2+}\right]_{\mathrm{c}}$ oscillations due to longer bursts instead of the characteristic fast oscillations in control and HFD-fed mice. This was reported previously [8] and suggested to be a consequence of a decrease in TRPM5 channel expression [9], which was also found in this study [4]. The fuel secretagogue alpha-ketoisocaproate produced similar $\left[\mathrm{Ca}^{2+}\right]_{c}$ changes as glucose, whereas $\mathrm{KCl}$ did not, again implying a crucial role of metabolism. Noteworthy, another recent study reported a decreased density of $\mathrm{K}_{\mathrm{ATP}}$ channels in the plasma membrane, which might also partly account for the observed left-shift [10]. Most importantly, comparison of $\left[\mathrm{Ca}^{2+}\right]_{\mathrm{c}}$ signals in individual beta cells revealed a reduced degree of synchronicity, as reported previously [8], and lower levels of connexin 36 [4]. Other studies have confirmed that genetic or dietary disruption of connexin 36-mediated intercellular coupling disrupts coordination of intercellular signaling, insulin secretion, and glucose tolerance [11]. At the end of the stimulus-secretion coupling cascade, a higher insulin gene expression and content, as well as enhanced exocytosis in response to depolarization pulses were observed in $o b / o b$ mice, indicating that the enhanced GSIS is also due to an increased sensitivity of the exocytotic machinery independently of the glucose metabolism [4]. In sum, the coupling among beta cells seems to be the only parameter that decreases during transition from compensated to partly decompensated insulin resistance. A decreased intercellular connectivity has been described in other genetic models of insulin resistance [12] and in human islets exposed to gluco(lipo)toxic conditions [13]. Our preliminary data from western diet induced diabetic mice confirm that disrupted intercellular connectivity is a hallmark of progression toward frank diabetes (Dolenšek J, Valladolid-Acebes I, et al., unpublished data).

\section{The Contribution of Chronic Kidney Disease to Beta Cell Dysfunction}

Insulin resistance is present in almost all and glucose intolerance in more than $50 \%$ of children and adults with chronic kidney disease (CKD). In CKD, insulin resistance has been demonstrated convincingly; however, contributions by decreased beta cell mass and dysfunction are much less clear. Using the 5/6 nephrectomy mouse model and ex vivo human islet studies, it was demonstrated that insulin secretion becomes impaired in experimental CKD without changes in beta cell mass or insulin content, indicating that beta cell dysfunction alone can be sufficient to bring about glucose intolerance. More specifically, glucose metabolism was impaired in these mice and human islets exposed to clinically relevant concentrations of urea due to reactive oxygen species production, $\mathrm{O}$-linked $\mathrm{N}$-acetyl glucosamine modification of phosphofructokinase- 1 and thus impaired glycolysis. Downstream in the stimulus-secretion coupling cascade, an attenuated rise in $\left[\mathrm{Ca}^{2+}\right]_{\mathrm{c}}$ and reduced insulin secretion were observed [14]. Factors other than urea can possibly contribute to impaired beta cell function and reduced GSIS in CKD [15]. Defective glucose metabolism in CKD leading to impaired GSIS can arise due to a reduced cellular ATP content owing to inhibition by an increased $\left[\mathrm{Ca}^{2+}\right]_{c}$ due to increased PTH-induced calcium entry into beta cells and reduced calcium extrusion as a result of calcium ATPase inhibition [16]. Furthermore, it has been demonstrated that vitamin D deficiency inhibits GSIS and that its supplementation can increase insulin levels in vivo [17]. In sum, CKD seems to impair beta cell function mostly at the most proximal step in the stimulus-secretion coupling cascade. To the best of our knowledge, intercellular coupling that may also play an important role in determining whole islet insulin output has not been studied in CKD. Moreover, to better assess the contribution of CKD to beta cell dysfunction in a setting of a metabolic syndrome, an experimental model with a stronger insulin resistance may be clinically more relevant. Deciphering the impact of insulin resistance, uremia, and other diabetogenic factors in CKD on beta cells may also help us better understand and treat post-transplant diabetes mellitus. People with insulin resistance seem to be at the greatest risk for developing diabetes after transplantation and this might be due to the initial beta cell dysfunction present at the time of transplantation [18]. Since the glycolysis-inhibiting protein O-linked $\mathrm{N}$-acetyl glucosamine-ylation is present in pancreatic sections of nondiabetic CKD patients, levels of uremia might be a risk factor for beta cell failure after transplantation [14]. Finally, recent studies suggest that both corticosteroids and tacrolimus directly interfere with beta cell stimulus-secretion coupling, possibly contributing to their failure $[19,20]$. Discerning the effect of immunosuppression on beta cells could influence therapeutic stratification in the future. 


\section{Conclusions}

Beta cells compensate for insulin resistance at many steps in intracellular signaling through the stimulus-secretion coupling cascade and this becomes even more pronounced with progression toward hyperglycemia. CKD can impair beta cell function at the most proximal step of glucose metabolism via oxidative stress, suggesting antioxidants as a promising therapeutic strategy to prevent dysfunction. An early negative marker of transition toward decompensation is disrupted intercellular connectivity, which may become an attractive therapeutic target in the future.

\section{Acknowledgment}

We acknowledge support from the Slovenian Research Agency (Programs I0-0029 and P3-0396, as well as projects N3-0048, J77226, J1-7009, and J3-9289).

\section{Disclosure Statement}

The authors have no conflicts of interest to disclose.

\section{References}

1 Skelin Klemen M, Dolenšek J, Slak Rupnik M, Stožer A: The triggering pathway to insulin secretion: functional similarities and differences between the human and the mouse $\beta$ cells and their translational relevance. Islets 2017;9:109-139.

2 Gonzalez A, Merino B, Marroquí L, Ñeco P, Alonso-Magdalena P, Caballero-Garrido E, Vieira E, Soriano S, Gomis R, Nadal A, Quesada I: Insulin hypersecretion in islets from diet-induced hyperinsulinemic obese female mice is associated with several functional adaptations in individual $\beta$-cells. Endocrinology 2013:154:3515-3524.

3 White MG, Shaw JA, Taylor R: Type 2 diabetes: the pathologic basis of reversible $\beta$-Cell Dysfunction. Diabetes Care 2016;39:20802088.

4 Irles E, Neco P, Lluesma M, Villar-Pazos S, Santos-Silva JC, Vettorazzi JF, Alonso-Magdalena P, Carneiro EM, Boschero AC, Nadal Á, Quesada I: Enhanced glucose-induced intracellular signaling promotes insulin hypersecretion: pancreatic beta-cell functional adaptations in a model of genetic obesity and prediabetes. Mol Cell Endocrinol 2015;404: 46-55.

5 Corkey BE: Banting Lecture 2011: Hyperinsulinemia: Cause or Consequence? Diabetes 2012;61:4-13.

6 Templeman NM, Flibotte S, Chik JHL, Sinha S, Lim GE, Foster LJ, Nislow C, Johnson JD: Reduced Circulating Insulin Enhances Insulin Sensitivity in Old Mice and Extends Lifespan. Cell Rep 2017;20:451-463.

7 Dolenšek J, Rupnik MS, Stožer A: Structural similarities and differences between the hu- man and the mouse pancreas. Islets 2015; 7:e1024405

8 Ravier MA, Sehlin J, Henquin JC: Disorganization of cytoplasmic $\mathrm{Ca}(2+)$ oscillations and pulsatile insulin secretion in islets from $o b / o b$ mice. Diabetologia 2002;45:1154-1163.

9 Colsoul B, Jacobs G, Philippaert K, Owsianik G, Segal A, Nilius B, Voets T, Schuit F, Vennekens R: Insulin downregulates the expression of the Ca2+-activated nonselective cation channel TRPM5 in pancreatic islets from leptin-deficient mouse models. Pflugers Arch 2014;466:611-621.

10 Park SH, Ryu SY, Yu WJ, Han YE, Ji YS, Oh K, Sohn JW, Lim A, Jeon JP, Lee H, Lee KH, Lee $\mathrm{SH}$, Berggren $\mathrm{PO}$, Jeon $\mathrm{JH}$, Ho WK: Leptin promotes $\mathrm{K}(\mathrm{ATP})$ channel trafficking by AMPK signaling in pancreatic $\beta$-cells. Proc Natl Acad Sci U S A. 2013;110:12673-12678.

11 Gosak M, Markovič R, Dolenšek J, Slak Rupnik M, Marhl M, Stožer A, Perc M: Network science of biological systems at different scales: a review. Phys Life Rev 2018;118-135.

12 Daraio T, Bombek LK, Gosak M, ValladolidAcebes I, Klemen MS, Refai E, Berggren PO, Brismar K, Rupnik MS, Bark C: SNAP-25bdeficiency increases insulin secretion and changes spatiotemporal profile of $\mathrm{Ca}^{2+}$ oscillations in $\beta$ cell networks. Sci Rep 2017;7: 7744 .

13 Johnston NR, Mitchell RK, Haythorne E, Pessoa MP, Semplici F, Ferrer J, Piemonti L, Marchetti P, Bugliani M, Bosco D, Berishvili E, Duncanson P, Watkinson M, Broichhagen J, Trauner D, Rutter GA, Hodson DJ: Beta cell hubs dictate pancreatic islet responses to glucose. Cell Metab 2016;24:389-401.
14 Koppe L, Nyam E, Vivot K, Manning Fox JE Dai XQ, Nguyen BN, Trudel D, Attané C, Moullé VS, MacDonald PE, Ghislain J, Poitout V: Urea impairs $\beta$ cell glycolysis and insulin secretion in chronic kidney disease. J Clin Invest 2016;126:3598-3612.

15 Nakamura Y, Yoshida T, Kajiyama S, Kitagawa Y, Kanatsuna T, Kondo M: Insulin release from column-perifused isolated islets of uremic rats. Nephron 1985;40:467-469.

16 Fadda GZ, Hajjar SM, Perna AF, Zhou XJ Lipson LG, Massry SG: On the mechanism of impaired insulin secretion in chronic renal failure. J Clin Invest 1991;87:255-261.

17 Clark SA, Stumpf WE, Sar M: Effect of 1,25 dihydroxyvitamin D3 on insulin secretion. Diabetes 1981;30:382-386.

18 Porrini EL, Diaz JM, Moreso F, Delgado Mallen PI, Silva Torres I, Ibernon M, Bayes-Genis B, Benitez-Ruiz R, Lampreabe I, Lauzurrica R, Osorio JM, Osuna A, Dominguez-Rollan R, Ruiz JC, Jimenez-Sosa A, Gonzalez-Rinne A, Marrero-Miranda D, Macia M, Garcia J, Torres A: Clinical evolution of post-transplant diabetes mellitus. Nephrol Dial Transplant 2016;31:495-505.

19 Fine NHF, Doig CL, Elhassan YS, Vierra NC, Marchetti P, Bugliani M, Nano R, Piemonti L, Rutter GA, Jacobson DA, Lavery GG, Hodson DJ: Glucocorticoids reprogram $\beta$-cell signaling to preserve insulin secretion. Diabetes 2018;67:278-290.

20 Lombardi A, Trimarco B, Iaccarino G, Santulli G: Impaired mitochondrial calcium uptake caused by tacrolimus underlies beta-cell failure. Cell Commun Signal 2017; $15: 47$
Beta Cell Functional Adaptation and Dysfunction in Insulin Resistance 